\title{
Long-Term Water Saturation of Asphalt Binder Based on Fly Ash
}

\author{
Lebedev Mikhail Sergeevich \\ High Technology Center \\ Belgorod State Technological University \\ named after V.G. Shukhov \\ Belgorod, Russia \\ michaelL1987@yandex.ru, lebedev.ms@bstu.ru
}

\author{
Kozhukhova Natalia Ivanovna \\ Department of Materials Science and Materials Technology \\ Belgorod State Technological University \\ named after V.G. Shukhov \\ Belgorod, Russia \\ kozhuhovanata@yandex.ru, kozhukhova.ni@bstu.ru
}

\begin{abstract}
The use of fly ash from power plants as a component of paving asphalt concrete has been studied by many scientists for over 100 years. However, there are conflicting data of their effect on properties of composites. The reason for this may be insufficient understanding of the role of fly ash composition, dispersity, structure and features of the structure formation process in asphalt compositions. The problem should be realized complexly. The current paper presents the detailed investigation of changes in the composition and structure of asphalt binder, occurred under continuously water saturation.

Experimental studies show the asphalt composite from the mixture of bitumen, and high-calcium fly ash (FA1) is characterized by a significant decrease in the strength characteristics, an increase in volume of absorbed water and volume of specimens under long-term water saturation. The author have found that the reason for this is low adhesion of organic binder to surface of fly ash particles, therefore the bituminous film flushes, the active minerals of fly ash, such as tricalcium aluminate, lime, portlandite, anhydrite, react with water and form new phases of ettringite, calcite and gypsum, that makes the structure less compact. Low-calcium fly ash (FA2) with the best adhesion to bitumen forms asphalt binder during longterm water saturation the composite is characterized by low dynamics of increasing water adsorption and reducing of strength. The structure of composite material is more stable in comparison with other compositions. Thus, the composition and adsorption capacity significantly affect water resistance of composites.
\end{abstract}

Keywords - fly ash from power plants, asphalt binder, water saturation, water resistance, new phases.

\section{INTRODUCTION}

In nowadays practice of building materials production, the unconventional raw materials are used carefully after a large number of studies [1]. All this is fully applicable to industrial waste (metallurgical, electric-power, chemical, mining, etc.), with characteristic properties and composition. However, interest to usage of these materials is very significant, taking into account their accumulated volumes and the possible reduction of energy and material resources. The latest conclusion is especially relevant relating to by-products with a "thermal history", such as fly ashes and slags, because they accumulate a certain amount of energy [2, 3]. Therefore, by now there is a sufficient experience of usage of these industrial wastes in composition of road asphalt concretes as well. Especially, this is actual for fly ash from thermal power plants, as far as they are highly dispersed materials, not required additional expenses for dispergation. So, they can be used as bitumen fillers. However, despite this, opinions of researchers on the influence on characteristics of road asphalt composites varies $[2,4-8]$. The reason for these conflicting data can be differences in composition, structure, dispersity, activity, adsorption capacity and other characteristics of these materials used as bitumen fillers. All these factors in complex are very important in the context of effective usage of fly ash in bitumenmineral composites. This article is a continuation of the author's research in the subject area [9]. Previously the significant differences in the formed structure and characteristics of asphalt binder when using fly ash with different composition (differ in calcium oxide content), dispersity [9] and adsorption capacity were determined. The last factor has a significant effect on properties of asphalt binders under water saturation, which was shown in swelling test [10]. This article presents the results of study that are similar to described ones in the last article, but they are devoted to detailed research of changes in composition and structure of asphalt binders, occurred at the time of long-term water saturation.

\section{EXPERIMENTAL PART}

\section{A. Materials}

The raw materials for asphalt binders were two types of fly ash from Russian thermal power plants Nazarovsk with a high content of calcium oxide (FA1) and Omsk - with a low content of calcium oxide (FA2), as well as road viscous bitumen with the penetration grade of $60 / 90 \mathrm{dmm}$ [9].

\section{B. Methods.}

The producing of asphalt binders and choice of optimal composition were carried out according to the Russian Standard, GOST R 52129-2003 [11]. Asphalt binders were obtained by mixing fly ash and bitumen at the temperature of 140-160 ${ }^{\circ} \mathrm{C}$, followed by forming from the mixture of cylindrical specimens with a diameter and a length of $25.2 \mathrm{~mm}$ in metal molds using hydraulic press under the load of $10 \mathrm{MPa}$ For each test and composition, 3 samples were prepared. Water saturation of specimens was performed according to Russian Standard, GOST 12801-98 [12]. First, the specimens were weighed in air, then placed in a container filled with water at a temperature of $(20 \pm 2){ }^{\circ} \mathrm{C}$ for 30 minutes, and then weighed in air and water. Then the specimens of asphalt binders were 
placed in the container of a vacuum unit filled with water in such a quantity that its level above the specimens was at least 3 $\mathrm{cm}$. The pressure was reduced to $0.002 \mathrm{MPa}$, and the specimens were kept for 1 hour. After this, the pressure was built up to atmospheric, and the specimens were kept in water for various times. To determine the short-term water saturation (during 1 day), this time interval was 30 minutes, for the long-term - 15 and 30 days. At the end of the experiment, the specimens were weighed in air and water. The water saturation value of asphalt binder specimens was calculated with equation (1):

$$
W=\frac{m_{3}-m_{0}}{m_{2}-m_{1}} \cdot 100 \%
$$

where $\mathrm{m} 0$ - mass of dry specimen (water unsaturated) weighed in air; $\mathrm{m}_{1}$ and $\mathrm{m}_{2}$ - mass of specimen (after 30 minutes in water) weighted in water and air, respectively; $\mathrm{m}_{3}-$ mass of specimen (water-saturated) weighted in air.

The volume of specimens of asphalt binders is equal to the volume of displaced water during weighing and was calculated as difference in the sample mass in air and water. Mass specific gravity is the ratio of specimen mass to its volume.

After the experiment on water saturation, asphalt binders specimens were tested for strength. In such a way the water resistance $\mathrm{K}$, which characterizes the degree of strength loss during saturation with water, was evaluated:

$$
K=\frac{R_{\text {water }}}{R_{20}}
$$

where $\mathrm{R}_{\text {water }}$ - compressive strength of specimens after water saturation; R20 - compressive strength of thermostated specimens at $20^{\circ} \mathrm{C}$.

Strength tests were carried out with test compact hydraulic press PGM-100MG4A with the maximum load of $100 \mathrm{kN}$ at a specimen deformation rate of $3 \pm 0.3 \mathrm{~mm} / \mathrm{min}$.

The study of the composition, structure and others parameters was carried out using the followings methods:

- X-ray diffraction analysis (XRD) with the ARL 9900 WorkStation with an embedded diffraction system. The study of specimens was performed on the Co-anode in the $2 \theta$ angle range from 8 to $80^{\circ}$. Minerals were identified using database PDF-2 (ICCD).

- IR-spectroscopy, using the Vertex 70 FTIR research spectrometer. The specimens for studies were the compressed tablets from the «bitumen-fly ash» mixture with potassium bromide. The result was the absorption spectra in the range of $400-4000 \mathrm{~cm}-1$.

- scanning electron microscopy using microscope TESCAN MIRA 3 LMU.

\section{RESULTS AND DISCUSSIONS}

\section{A. Water saturation and water resistance of asphalt binders}

The water saturation test is the basic one when selection of the optimal composition of asphalt binder according to Russian Standard GOST R 52129-2003 [11]. The quantity of absorbed water during a short-term experiment should be in a range of 4 to $5 \%$ of the specimen volume. According to results of previous studies the following compositions were selected:

- for high-calcium fly ash (FA1) - 18.5 (by wt.\%) bitumen over $100 \%$ fly ash;

- for low-calcium fly ash (FA2) - 37 (by wt.\%) bitumen over $100 \%$ fly ash [9].

Selected compositions were used for long-term water saturation tests.

The test for water resistance after short-term water saturation showed that the strength loss on asphalt binders based on FA1 is slightly lower (19\%) than for FA2 $(28 \%)$. However, both values satisfy the requirement of Russian Standard GOST R 52129-2003 (no more 30\%) [11]. Most probably, the results are explained by different content of solid phase and, accordingly, differences in packing density of particles in the structure of the bitumen-mineral material. Under long-term water saturation, the relationship character was changed greatly (Fig. 1). In the FA2-based composite, the value of water saturation evenly increased from $4 \%$ to $6.9 \%$ for 15 days and to $8.1 \%$ for 30 days. This may be due to progressive filling of voids and air pores with water in time. The composition on FA1 also quite evenly increases water saturation. However, the values greatly exceeded the composition of another fly ash $-18.4 \%$ for 15 days and $30 \%$ for 30 days.

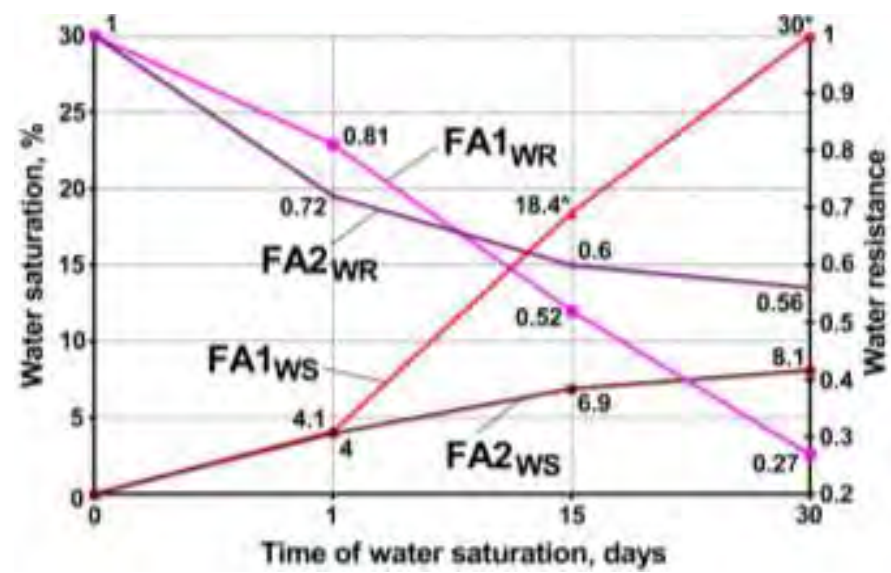

Fig. 1. Dependency diagram of water resistance (WR) of FA-based asphalt binders and the volume of absorbed water (WS) on the duration of water saturation: 1 day - short-term water saturation; * - water saturation values due to changes in specimen's mass as a result of hydration

These differences influence water resistance. FA2-based asphalt binder is characterized by a rather low dynamics of strength reduction. The short-term water resistance (after 1 day) was 0.72 ; after 15 days -0.6 , and after 30 days -0.56 . That is, after 30 days, the strength reduction was only $16 \%$. 
FA1-based composition after short-term water saturation demonstrates reduced strength by $19 \%$, after 15 days $-48 \%$, and after 30 days $-73 \%$. So, for 30 days of water saturation the asphalt binders after vacuuming, their strength was reduced by $54 \%$ vs. initial strength. This can be explained by low adsorption capacity of original fly ash that determines the bad adhesion of bitumen to surface of mineral particles [10]. Flaking of bitumen film can lead to changes in composition of filler due to hydration of active minerals. It is most probably that a significant strength decreases is due to formation of new phases in the system, and the values of water saturation do not demonstrate the real volume of absorbed water, since the composition and density of the phases is changed.

\section{B. Changes in structural parameters during water saturation}

The differences in water saturation and water resistance values of the compositions based on different fly ashes are reflected in structural parameters of asphalt binders, in particular, the mass specific gravity and volume change. The composite material based on low-calcium fly ash is characterized by gradual small increase in density from 1.540 $\mathrm{g} / \mathrm{cm} 3$ on initial specimens to $1.590 \mathrm{~g} / \mathrm{cm}^{3}$ after 30 days (Fig. 2 ), which is due to filling of air pores with water. There is a high correlation $\left(\mathrm{R}_{2}=0.99\right)$ between mass specific gravity of specimens and water saturation values. The structure of material was stable, there was no visible change in volume; increase in volume after 30 days of water saturation was $2.3 \%$. Probably, there were no significant changes in composition of filler.

Asphalt binder based on high-calcium fly ash after shortterm water saturation demonstrated an increased density from 2.068 to $2.097 \mathrm{~g} / \mathrm{cm}^{3}$ (Fig. 2). This is a result of filling air pores with water, which also occurred in composite material based on FA2.

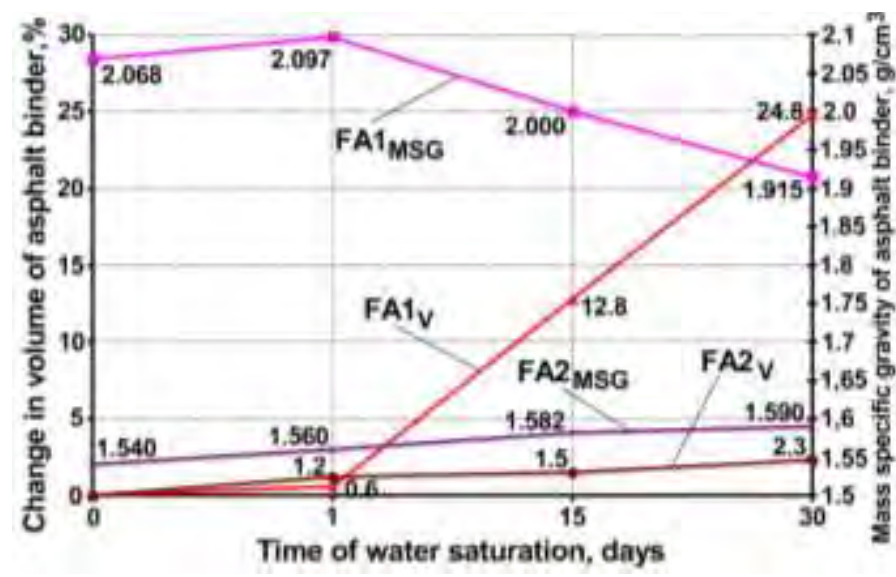

Fig. 2. The change in volume (V) and mass specific gravity (MSG) of specimens of FA-based asphalt binders from duration of water saturation: 1 day - short-term water saturation

Also there was no significant change in volume, slight swelling of specimens $(0.6 \%)$ turned out to be less than on other composition $(1.2 \%)$, which can be explained by more compact packing of particles and, consequently, a higher mass specific gravity of asphalt binder. At this stage, changes in composition of fly ash due to the hydration of active minerals were not presented, or processes were in the initial stage. At 15th and 30th day, increasing in water saturation values and reduction of mass specific gravity of bitumen-mineral material to 1.915 $\mathrm{g} / \mathrm{cm}^{3}$, i.e. by $7.4 \%$ vs. initial density was observed. As noted in section III.A, the observed decompaction leads to decrease in strength characteristics. The reason for this can be formation in the system of new unwanted phases after hydration of certain fly ash minerals. As a result of these processes, there was a significant volume increase in asphalt binder's specimens up to $12.8 \%$ after 15 days and 24.8\% after 30 days (Fig. 2). Subsequently, they cracked due to inner stresses that was determined visually. Decreasing of specific gravity can be initiated not only by change in composition of solid phase of binders, but also by additional absorption of water due to structure transformation of material and possible dissolution and removal of certain substances.

\section{The study of phase composition of asphalt binders}

It is necessary to discuss the processes of phase formation, which occur in the studied systems under the influence of penetrating water during all period of water saturation. For this purpose, asphalt binder specimens were studied before and after water resistance tests after short-term, 15-day and 30-day water saturation using X-ray diffraction analysis, infrared spectroscopy and scanning electron microscopy for each composition (Fig. 3, 4).

In bitumen-mineral composite based on low-calcium fly ash FA2, no changes in phase composition were found (Fig. 3). The appearance of reflections of sassolite (boric acid) on XRD pattern of bitumen-mineral composites is associated with contamination of test specimen with this product at the preparation stage.

Insignificant differences of relative intensities in IR spectra (the spectra was normalized by absorption band of stretching vibrations of $\mathrm{Si}-\mathrm{O}-\mathrm{Si}(\mathrm{Al})$ bridge bonds $1083 \mathrm{~cm}-1)$ related to peaks responsible for deformation vibrations (change in bond angle) $\mathrm{Si}-\mathrm{O}-\mathrm{Si}$ (Al) $(\sim 460 \mathrm{~cm}-1)$ and stretching vibrations (change in bond length) of aluminum in octahedron $(\sim 565 \mathrm{~cm}-$ $1)$, aluminum $(\sim 730 \mathrm{~cm}-1)$, and silicon $(\sim 792 \mathrm{~cm}-1)$ in tetrahedron $[13,14]$.

According to SEM results, after short-term water saturation, the microstructure is not much different from the initial one. The predominant structural units are aluminosilicate microspheres, which are nanostructured substance (i.e. X-ray amorphous), consisting of silicate clusters with different degrees of polymerization [15]. Adsorption capacity with respect to bitumen may depend on from degree of coherency of vitreous phase. After 15 and 30 days of water saturation, the bitumen film flaking as a resulted mineral surface becomes visible with appearance of finely dispersed formations on it, probably of amorphous structure. It is difficult to determine a genesis of these phases. 


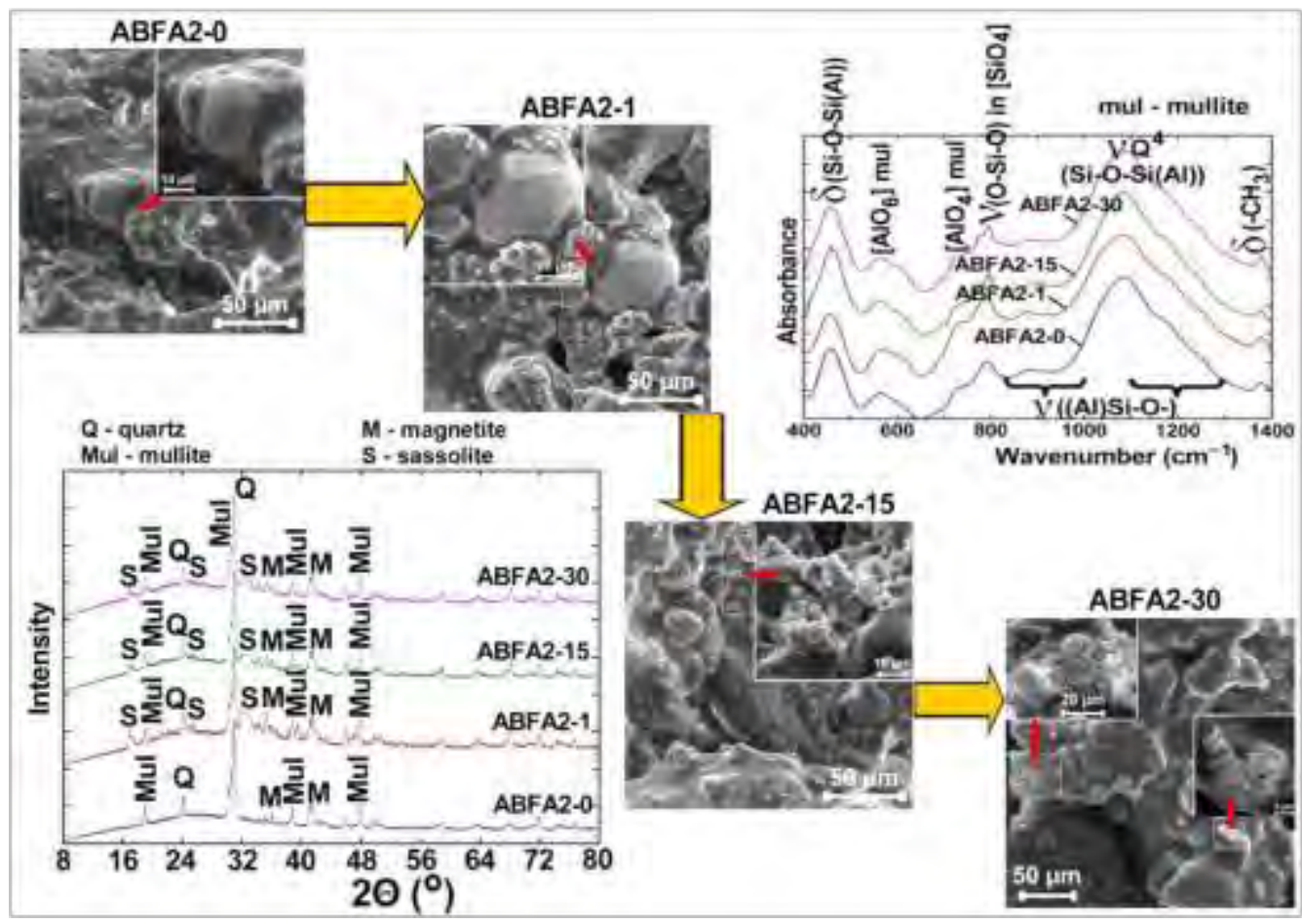

Fig. 3. Changes in composition and structure of asphalt binder based on FA2 as a result of water saturation: ABFA2-0 - asphalt binder before water saturation; ABFA2-1 - asphalt binder after 1 day of water saturation; ABFA2-15 - asphalt binder after 15 days of water saturation; ABFA2-30 - asphalt binder after 30 days of water saturation
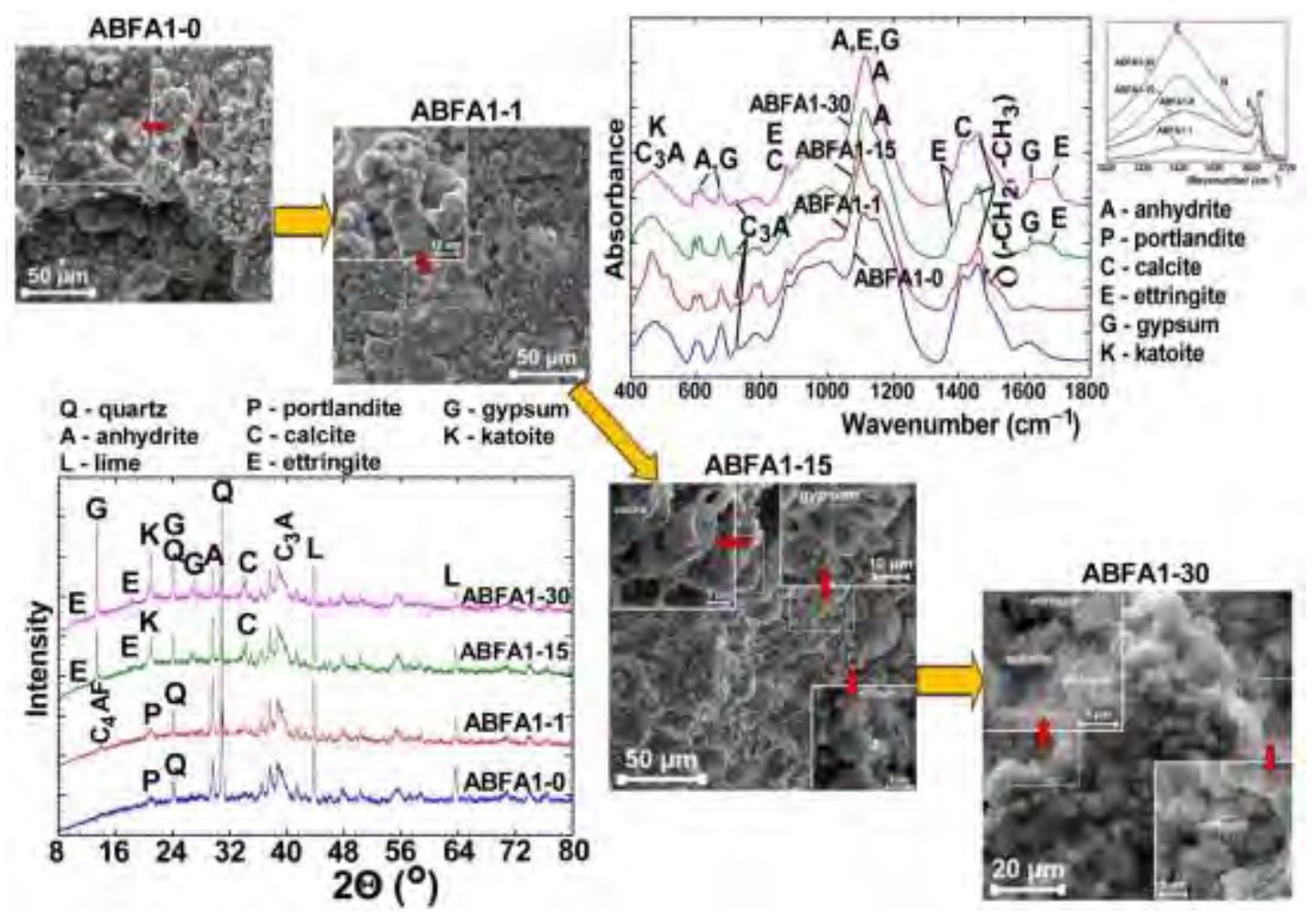

Fig. 4. Changes in composition and structure of asphalt binder based on FA1 as a result of water saturation: ABFA1-0 - asphalt binder before water saturation; ABFA1-1 - asphalt binder after 1 day of water saturation; ABFA1-15 - asphalt binder after 15 days of water saturation; ABFA1-30 - asphalt binder after 30 days of water saturation 
In case of asphalt binder, based on high calcium fly ash, a more complex picture was observed (Fig. 4). As expected, active minerals of initial fly ash, such as lime, anhydrite, tricalcium aluminate, were hydrated; the new phases were formed in the system, the structure changed also. However, after short-term water saturation, no significant changes were found. According to XRD data, lime intensity decreases slightly, areas under main peak of anhydrite (slightly reduced) and portlandite (slightly increased) changed. The IR spectra showed that intensity of absorption bands of anhydrite decreases (1149 and $676 \mathrm{~cm}-1$, and band at $606 \mathrm{~cm}-1$ decreases and is divided by 594 and $612 \mathrm{~cm}-1$ ), intensity of peaks characterizing the octahedral structures of tricalcium aluminate (464, $512 \mathrm{~cm}-1)$ increased. It can be associated with their transition to excited state [13]. But, probably, new hydrated phases were absent.

After 15 and 30 days of keeping the bitumen-mineral system in water, the new phases appeared, which can be diagnosed by all applied research methods (Fig. 4). These were ettringite, gypsum, katoite (the mineral from the group of garnets), calcite. The content of the last phase according to XRD data significantly increases in relation to the initial state. According to reflections on the XRD pattern, the sufficiently large-size crystallites of described minerals are present. On IR spectra the bands, characterizing these phases: $875,1115,1378,1414$, 1640, 1677, 3414, $3630 \mathrm{~cm}-1$ (ettringite); 611, 670, 1115, $1620,3555 \mathrm{~cm}-1$ (gypsum); $3642 \mathrm{~cm}-1$ (portlandite superposed on absorption band of ettringite); $875,1414 \mathrm{~cm}-1$ (calcite); 400-550 cm-1 (AlO6 vibration in katoite) were diagnosed [13].

SEM-analysis of the microstructure clearly showed the flaking of bitumen film from the surface of mineral particles and forming in these places the new phases of ettringite, gypsum and calcite (Fig. 4). Similar changes in the composition and structure were identified after the swelling experiment, where processes of hydration and phase formation were accelerated by exposure in hot water [10].

\section{CONCLUSIONS}

The studies presented in the article are of interest from the point of view of predictive assessment of binder application for asphalt concrete from the mixture of bitumen with filler to resist destructive water action, which always takes place in actual operating conditions. This is especially important when using non-conventional mineral fillers, such as fly ash. It was found that composition and adsorption capacity significantly influnce water resistance of composites. Asphalt binder based on lowcalcium fly ash with good adhesion to bitumen film is characterized by low dynamics of increasing water saturation and reducing strength. Low values of strength characteristics are associated with filler dispersity and its packing density in composite. High-calcium fly ash adsorbs bitumen less intensively that leads to flaking of bitumen film from the particles surface, hydration of active minerals and formation of unwanted new phases, such as ettringite. The growth of last phase leads to significant increase in the specimen's volume of asphalt binders, their decompaction, cracking and, consequently, reducing strength. Thus, it can be assumed that asphalt concrete using asphalt binder based on low-calcium fly ash will be more durable.

\section{Acknowledgment}

This research work is financially supported by the Ministry of Education and Science of the Russian Federation in the framework of State Assignment, №11.9329.2017/8.9, using equipment of High Technology Center at BSTU named after V.G. Shoukhov.

\section{References}

[1] I. Flores-Vivian, R. G.K. Pradoto, M. Moini, M. Kozhukhova, V. Potapov and K. Sobolev, "The effect of $\mathrm{SiO}_{2}$ nanoparticles derived from hydrothermal solutions on the performance of portland cement based materials", Frontiers of Structural and Civil Engineering, vol. 11 (4), 2017, pp. 436-445.

[2] G.A. Rasstegayeva, Active and activated mineral fillers produced from industrial waste. Voronezh. 2002, 192 p.

[3] K. Sobolev, M. Kozhukhova, K. Sideris, E. Menéndez and M. Santhanam, "Alternative supplementary cementitious materials", RILEM State-ofthe-Art Reports, vol. 25, 2018, pp. 233-282.

[4] E.I. Putilin and V.S Tsvetkov, Application of fly ashes and bottom-ash mixtures when road construction: review of domestic and overseas experience of using of solid-fuel combustion wastes from power stations. Moscow: Sousdornii, 2003.

[5] F.V. Zimmer, "Fly Ash as a Bituminous Filler", Proceedings of the Second Ash. Utilization Symposium", 1970, pp. 49-76.

[6] S.A. Simms, "Use of coal fly ash in asphalt concrete mixes", Halifax: DalTech-Dalhousie University, 1998.

[7] K. Sobolev, F. Ismael, R. Saha, N.M. Wasiuddin and N.E. Saltibus, "The effect of fly ash on the rheological properties of bituminous materials", Fuel, vol. 116, 2014, pp. 471-477.

[8] L.A. Urkhanova and A.V. Btuyev, "Use of fly ash Gusinoozersk power station as a mineral filler for asphalt concrete", Bulletin of Siberian State Automobile and Highway University, vol. 4-26, 2012, pp. $60-65$.

[9] M.S. Lebedev, N.I. Kozhukhova and I.L. Chulkova, "Effect of phase and size characteristics of fly ash from power station on properties of bitumen composites", IOP Conf. Series: Materials Science and Engineering, vol. 222, 2017.

[10] M.S. Lebedev and I.L. Chulkova, "Study of structure formation in bitumen-mineral compositions based on fly ash under water saturation", Advances in Engineering Research, vol. 133, pp. 403-408.

[11] Russian Standard 52129-2003, "Mineral powders for asphaltic concrete and organomineral mixtures. Specifications", Moscow: Russian Gosstroy, 2004.

[12] Russian Standard 12801-98, Materials on the basis of organic binders for road and airfield construction. Test Methods, Moscow: Russian Gosstroy, 1999.

[13] Lucia Fernández-Carrasco, D. Torrens-Martín, L.M. Morales and Sagrario Martínez-Ramírez, "Infrared Spectroscopy in the Analysis of Building and Construction Materials", Infrared Spectroscopy - Materials Science, Engineering and Technology, InTech, 2012, pp. 369-382.

[14] A. Chaisena, "Synthesis of sodium zeolites from lampang diatomite applied for ammonium ion removal", A Thesis Submitted in Partial Fulfillment of the Requirements for the Degree of Doctor of Philosophy in Chemistry, Suranaree University of Technology, Nakhon Ratchasima, Thailand, 2004.

[15] N.I. Kozhukhova, I.V. Zhernovsky and K.G. Sobolev, "Effect of variations in vitreous phase of low-calcium aluminosilicates on strength properties of geopolymer systems", Bulletin of BSTU named after V.G. Shoukhov, vol. 4, 2018, pp. 5-12. 